\title{
CONJUNCTIVAL AUTOGRAFT VERSUS TOPICAL MITOMYCIN C IN TREATMENT OF PTERYGIUM
}

\author{
P. S. MAHAR \\ Tabuk, Saudi Arabia
}

\begin{abstract}
SUMMARY
A prospective study was carried out to assess the recurrence rate of pterygium with conjunctival autograft versus the use of topical mitomycin C. In 27 eyes undergoing pterygium excision with conjunctival autograft, the recurrence rate was found to be $25.9 \%$ after 1 year mean follow-up. In the second group of 32 eyes, pterygium was removed using the bare sclera method. All these patients received post-operatively $0.2 \mathrm{mg} / \mathrm{ml}$ $(0.02 \%)$ topical mitomycin $C$ twice a day for 5 days. At 1 year mean follow-up, the recurrence rate in this group was $9.4 \%$. Although the difference was not statistically significant, the number of recurrences was lower in the mitomycin-C-treated group than in patients undergoing conjunctival autograft.
\end{abstract}

Conjunctival transposition after pterygium excision has been described by many authors but was popularised by Kenyon et al. ${ }^{1}$ They used free conjunctival graft from the supero-temporal conjunctiva of the same eye to resurface the exposed sclera after pterygium excision. Over the past decade we have also witnessed the use of topical mitomycin $\mathrm{C}$ as an adjunctive treatment after pterygium excision with good results. From our own previous study ${ }^{2}$ comparing the use of topical mitomycin $\mathrm{C}$ after pterygium excision with simple pterygium excision in a group of 30 patients, no recurrence was found in the mitomycin $\mathrm{C}$ group. Since then this drug has been used regularly as an adjunctive treatment after pterygium excision in our unit. This prospective study was conducted to compare the recurrence rate of pterygia after conjunctival autotransplant against pterygium excision with post-operative use of mitomycin $\mathrm{C}$ drops.

\section{SUBJECTS AND METHODS}

From January 1991 patients visiting the eye clinic at

From: Armed Forces Hospital, Tabuk, Saudi Arabia.

Correspondence to: Dr P. S. Mahar, FRCS, FRCOphth, Division of Ophthalmology, Department of Surgery, The Aga Khan University Hospital, Stadium Road, PO Box 3500, Karachi 74800, Pakistan. the Armed Forces Hospital, Tabuk, requiring pterygium surgery were entered in this study. All patients were military personnel or their spouses. Permission for the study was granted by the hospital's Ethical and Credential Committee. The decision to carry out pterygium excision was made once pterygia were noticed to be vascularised and fleshy in nature, and encroaching over the cornea for a minimum of 2-3 mm. Atrophic and non-progressive pterygia were excluded. Most of these patients complained of irritable, red eyes and had been using topical vasoconstrictor and other astringent solutions.

The patients were randomly allocated to two groups irrespective of their age and sex. There were some patients with pterygia in both eyes requiring surgery. It was not possible to randomise these into different treatment groups on an individual eye basis as some patients refused to accept different modes of treatment for their two eyes. Therefore, randomisation had to be carried out on a patient basis. All pterygia were primary in nature, situated nasally. Pterygia of a recurrent nature were excluded from the study. The first procedure was performed in January 1991 and last in June 1992. All patients had an ocular examination post-operatively using slit lamp biomicroscopy at 1 week, 2 weeks, 4 weeks and then 8-12 weeks.

\section{Group I}

In group I 27 eyes of 22 patients had pterygium excision with conjunctival autograft. The operative procedure adopted was that described by Kenyon $e t$ $a l .{ }^{1}$ All patients had surgery under retrobulbar block using the operating microscope. Post-operatively all patients received Maxitrol (Alcon) ointment 3 times a day for 2-3 weeks.

\section{Group II}

In group II 32 eyes of 28 patients had their pterygia removed using the bare sclera technique. The operative procedure as described by Mahar and' 
Table I. Background characteristic of patients

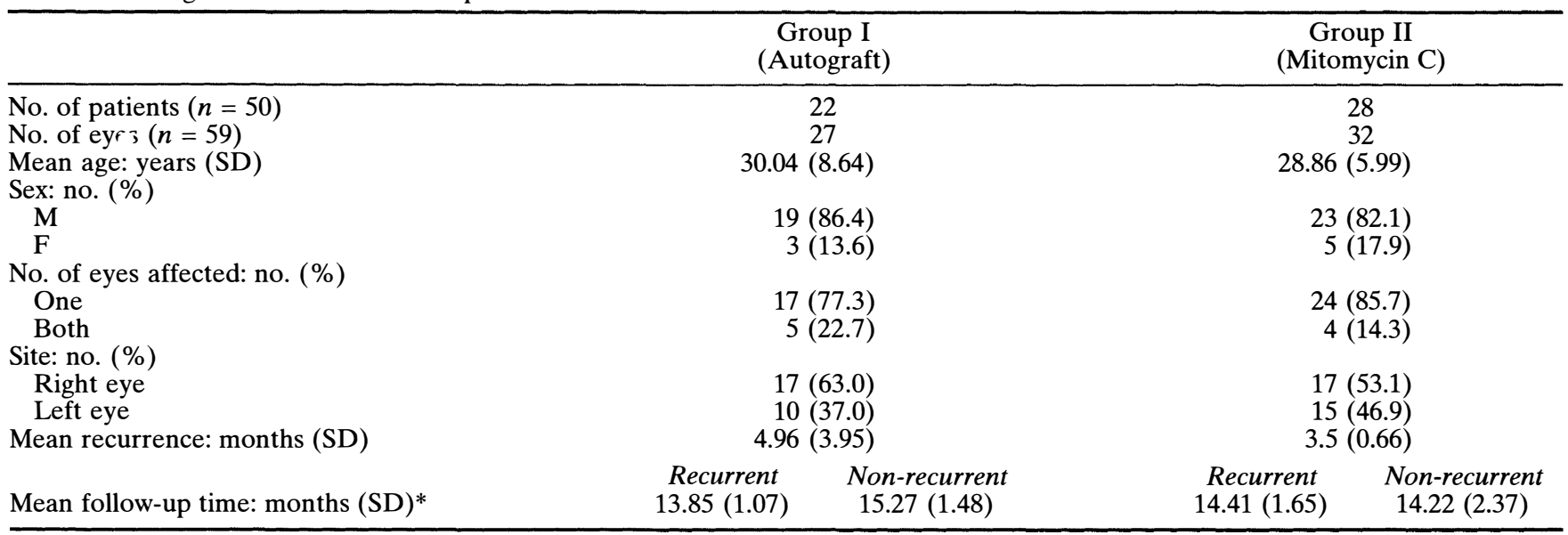

${ }^{*} p<0.05$.

Nwokora $^{2}$ was adopted. Post-operatively, all patients received $0.2 \mathrm{mg} / \mathrm{ml}(0.02 \%)$ mitomycin $\mathrm{C}$ drops, one drop twice a day for 5 days, along with Maxitrol ointment twice a day for 2-3 weeks.

\section{Outcome}

Outcome of the surgery was classified as follows:

R1: No recurrence or mild vascularisation of the graft or pterygium site.

R2: Recurrence of frank pterygium encroaching over the cornea or moderate to severe vascularisation of the graft or pterygium site causing cosmetic blemish.

The result of the surgery was claimed as a success for patients in the R1 group; patients classified in the R2 group were considered as failures.

\section{RESULTS}

The data were collected and processed using the SPSS (Statistical Package for the Social Services). The chi-squared test, $t$-test and ANOVA were used to check for significant differences between the variables (Table I).

In group I, 27 eyes of 22 patients were treated. The age range was 19-48 years (mean 30 years). Nineteen patients were male and 3 were female. Recurrence of frank pterygium was seen from 6 weeks to 6 months time (mean 4.96 months). All patients were followed up for 12-18 months. Mean follow-up time was 13.85 months in cases showing recurrence and 15.27 months in non-recurring cases.

Of the 27 eyes in group I 14 did not show any sign of recurrence, while 6 eyes showed some vascularisation over the pterygium site that caused neither any cosmetic blemish nor any symptoms to the patient (R1). This group of patients was termed as having a successful outcome of surgery $(74.1 \%)$. On the other hand, 6 eyes had complete recurrence of pterygia, while 1 eye had sufficient vascularisation for the patient to complain of a red and irritable eye. These
7 patients (R2) indicated a recurrence rate of $25.9 \%$. In all recurrences the pterygium head was seen invading the graft directly; however, in one case the pterygium head was seen crossing above the graft reaching the cornea.

In group II, 32 eyes of 28 patients were treated. The age range was 20-39 years (mean 28.86 years). Twenty-three patients were male and 5 were female. Follow-up time was 14.41 months in patients showing recurrence and 14.22 months in patients with no recurrence. No frank recurrence was seen in any case but 3 eyes had severe vascularisation involving the graft site with an unacceptable cosmetic outcome to the patient (R2). Overall recurrence was thus seen in $9.4 \%$ of cases. In 3 eyes a little vascularisation was noted post-operatively, but patients remained cosmetically satisfied and symptomless. These 3 eyes, along with the 26 eyes with no recurrence $(91.6 \%$ of group II), were classified as having a successful outcome of the treatment (R1) (Table II).

All patients were advised to use a dose of only one drop of mitomycin C. They were all given an appointment on the fifth day of the mitomycin therapy and were instructed to bring the bottle with the remaining mitomycin back to the clinic. The drug was tolerated very well, though a few patients did complain of a stinging sensation on instilling the drops. Epithelisation over pterygium site was observed 2-3 weeks after surgery. No scleral or corneal complications were seen in patients throughout their follow-up.

Table II. Results of treatment

\begin{tabular}{lcc}
\hline & $\begin{array}{c}\text { Group I } \\
\text { (Autograft) }\end{array}$ & $\begin{array}{c}\text { Group II } \\
\text { (Mitomycin C) }\end{array}$ \\
\hline No. of patients & 22 & 28 \\
No. of eyes & 27 & 32 \\
R1: no. (\%) & $20(74.1)$ & $29(91.6)$ \\
R2: no. (\%) & $7(25.9)$ & $3(9.4)$ \\
\hline
\end{tabular}

$\mathrm{R} 1$, no recurrence; $\mathrm{R} 2$, recurrence. 


\section{DISCUSSION}

Pterygium remains one of the common corneal disorders in subtropical and tropical areas. Although topical thiotepa, beta-radiation and laser treatment have been used as adjunctive treatments to reduce the recurrence rate of pterygia after surgery, transferring a free graft of supero-temporal conjunctiva to cover the sclera exposed by pterygial excision has been practised much more extensively by many with reported good results. Kenyon et al. ${ }^{1}$ reported a $5.3 \%$ recurrence rate in their group of 57 eyes undergoing conjunctival autograft, although one of the reservations about this outcome is that in the particular geographic area of the study pterygium is less malignant in terms of its incidence and severity of recurrence. In the series by Polit and Matheen ${ }^{3}$ a $7.5 \%$ recurrence rate was shown in 80 eyes undergoing conjunctival autograft. All patients in these series were taken from the civilian population. In our group of patients a recurrence rate of $24.9 \%$ was seen in patients undergoing autograft. This figure appears high compared with the other studies, but this can be attributed to the type of population treated in our study. All male patients in our series were army personnel belonging to the high-risk group of patients as suggested by Mackenzie et al. ${ }^{4}$ - that is working outdoors in an environment with high surface reflectance of ultraviolet light and working mainly on sand.

Interestingly, in our study all recurrences were witnessed in male patients while no recurrence was seen in females, who stay indoors most of the time in Saudi Arabia.

Over the last decade we have seen an upsurge in the use of topical mitomycin $\mathrm{C}$ in pterygium surgery. The recurrence rate after its use has been very low compared with other forms of adjunctive therapy. In a group of patients treated with topical mitomycin C $(0.2 \mathrm{mg} / \mathrm{ml})$ Hayasaka et $_{\text {al }}{ }^{5}$ showed a $7 \%$ recurrence rate, compared with a $15 \%$ recurrence rate in patients having excision and radiation therapy. Sing et $a .^{6}{ }^{6}$ showed a significant decrease in recurrence rate after mitomycin $\mathrm{C}$ use compared with patients receiving placebo only. Our own group of 15 patients using $0.4 \mathrm{mg} / \mathrm{ml}$ mitomycin $\mathrm{C}$ showed no recurrence at all. ${ }^{2}$ Recently Frucht-Pery and Islar $^{7}$ have shown a $4 \%$ recurrence of pterygia in patients receiving 0.2 $\mathrm{mg} / \mathrm{ml}$ mitomycin $\mathrm{C}$ drops compared with a $20 \%$ recurrence rate in the group receiving 1200 rads beta-radiation. Thus the recurrence rate of $9.4 \%$ in our patients appears to be comparable to the results in other studies.

Although some serious complications have been shown to occur in patients receiving mitomycin $\mathrm{C}$ drops, ${ }^{8,9}$ these patients were using mitomycin C either in higher concentration or for longer durations. The author has also witnessed cataract formation, corneoscleral ulcers and scleral perforation in patients using mitomycin drops inadvertently for a period of 4 weeks. ${ }^{10}$ However, the incidence of such complications is negligible if patients are observed closely. The specific instructions to use one drop at a time, and to bring the mitomycin container back to the clinic on the first appointment, have definitely worked very well for us and we feel that we have successfully reduced the incidence of patients using the drug for an extended period inadvertently. Although statistically not significant, the number of patients showing recurrence was lower in the group treated with topical mitomycin $\mathrm{C}$ than in patients undergoing conjunctival autograft. More studies have to be performed on the use of topical mitomycin $\mathrm{C}$ to standardise its dose in pterygium surgery to avoid any unwanted effects. However, due to the simplicity of its use, topical mitomycin C remains the treatment of choice following excision of pterygia, with excellent results compared with other types of adjunctive therapy.

I am grateful to Ms Saida Bano for typing the manuscript.

Key words: Pterygium, Autograft, Mitomycin C.

\section{REFERENCES}

1. Kenyon KR, Wagoner MD, Hettinger ME. Conjunctival autograft transplantation for advanced and recurrent pterygium. Ophthalmology 1985;92:1461-70.

2. Mahar PS, Nwokora GE. Role of mitomycin $C$ in pterygium surgery. Br J Ophthalmol 1993;77:433-5.

3. Polit F, Matheen M. Conjunctival autograft for advanced and recurrent pterygium in Saudi Arabia. Saudi J Ophthalmol 1991;5:171-4.

4. Mackenzie FD, Hirst LW, Battistutta D, Green A. Risk analysis in the development of pterygia. Ophthalmology 1992;99:1056-61.

5. Hayasaka S, Noda S, Yamamoto Y, Setogawa T. Postoperative instillation of low dose mitomycin $\mathrm{C}$ in the treatment of primary pterygium. Am J Ophthalmol 1988;106:715-8.

6. Sing G, Wilson MR, Foster CS. Mitomycin eye drops as treatment for pterygium. Ophthalmology 1988;95: 813-20.

7. Frucht-Pery J, Islar M. The use of low dose mitomycin C for prevention of recurrent pterygium. Ophthalmology 1994;101:759-62.

8. Rubinfeld RS, Pfister RR, Stein RM. Serious complications of topical mitomycin $\mathrm{C}$ after pterygium surgery. Ophthalmology 1992;99:1647-54.

9. Gupta S, Bastis S. Corneoscleral, ciliary body and vitreoretinal toxicity after excessive instillation of mitomycin C. Am J Ophthalmol 1992;114:503-5.

10. Mahar PS. Role of mitomycin $C$ in reducing the recurrence of pterygium after surgery. Pak J Ophthalmol 1996;12:113-6. 